\title{
Thermal Analysis as a Useful Tool in Drug-Excipient Compatibilty Studies: The Impact in Pharmaceuticals Products
}

\author{
Douglas Dourado* \\ Graduate Program in Pharmaceutical Nanotechnology, Brazil \\ *Corresponding author: Douglas Dourado, Graduate Program in Pharmaceutical Nanotechnology, Brazil
}

\begin{tabular}{|c|c|}
\hline ARTICLE INFO & ABSTRACT \\
\hline Received: 慧 October 26, 2019 & \multirow{3}{*}{$\begin{array}{l}\text { This mini-review discusses the importance of thermal analysis as a predictive tool } \\
\text { for pharmaceutical stability in the design of drug-excipient compatibility studies. In this } \\
\text { regard, aspects regarding the need for preformulation studies recommended by the FDA } \\
\text { were discussed, revealing thermo analytical techniques such as TGA / DTG and DSC as } \\
\text { rapid analyses, with little sample consumption and reliable responses. The main idea } \\
\text { of this expert opinion is to show the need for drug-excipient compatibility studies and } \\
\text { their impacts on the efficacy, toxicity and stability of pharmaceutical products that can } \\
\text { be readily identified through the tools cited herein. Thus, drug-excipients compatibility } \\
\text { studies are encouraged as predictors of the stability of the final pharmaceutical product. }\end{array}$} \\
\hline Published: 蔧October 31, 2019 & \\
\hline $\begin{array}{l}\text { Citation: Douglas Dourado. Thermal Anal- } \\
\text { ysis as a Useful Tool in Drug-Excipient } \\
\text { Compatibilty Studies: The Impact in Phar- } \\
\text { maceuticals Products. Biomed J Sci \& Tech } \\
\text { Res } 22(3)-2019 . \text { BJSTR. MS.ID.003745. }\end{array}$ & \\
\hline & $\begin{array}{l}\text { Abbreviations: ICTAC: International Confederation of Thermal Analysis; DSC: Differen- } \\
\text { tial Scanning Calorimetry; TGA: Thermogravimetry }\end{array}$ \\
\hline
\end{tabular}

\section{Mini Review}

For the development of a new formulation FDA requires preformulation studies such as drug-excipient compatibility in order to predict possible instability phenomena in the targeted end product. This is important for understanding physical and chemical interactions between drugs and excipients that may influence the chemical nature, stability, solubility and absorption of the drug in vivo and the safety and efficacy of the pharmaceutical product [1]. Such studies promote the ideal choice of components and quantities of a formulation, identify degradation products and improve the understanding of reactions [2]. When observed interactions that promote modification of physical or chemical form to a less favourable state, which consequently lead to inactivation of the drug, or produce degradation products, there is an incompatibility, which negatively affects the therapeutic efficacy and safety of the developed product [3]. Drug-excipient compatibility studies are performed from the evaluation of pure isolated samples and their physical mixtures. Usually, binary mixtures are evaluated in a 1:1 ratio, which allows the intensification of interactions, consequently better visualization of possible instability phenomena over time. Some works also evaluate ternary mixtures in order to observe the maximum interactions in the complexity of excipients and drug present in the final product [4].

The most widely used techniques to verify incompatibilities between the drug and excipient are the thermal analysis. According to International Confederation of Thermal Analysis (ICTAC) and IUPAC, thermal analysis is a term that encompasses a group of techniques which a physical or chemical property of a substance or its reaction products is monitored as a function of time or temperature, while the temperature of the sample under an atmosphere is subject to controlled programming [5]. The use of thermo analytical techniques has increased in the field of pharmaceutical development, being used for the characterization of excipients and the development of formulations [6]. They have numerous advantages in the interaction studies between active ingredient and excipients, study of degradation kinetics and stability of pharmaceutical forms, among other applications [7,8]. Among the many thermo analytical techniques, it is worth mentioning the Differential Scanning Calorimetry (DSC) and thermogravimetry (TGA/DTG). TGA is a technique where the loss or mass gain of the sample is evaluated as a function of temperature or time. DTG refers 
to the first derivative of TGA as a function of time or temperature, a curve which more clearly shows the degradation events that may be overlapping in the TGA.

This technique can be coupled with microscopes that provide time-dependent imaging, infrared and mass spectrometry that can elucidate and quantify generated products as well as sample integrity [9]. In the compatibility studies this analysis allows to observe the thermal degradation profile of the drug, the excipients and the mixtures between them. Factors such as drug protection, reactions, intermediate and end-residue degradation products generated and degradation kinetics can be evaluated [10]. In addition to TGA / DTG analysis, there is DSC, a thermo analytical technique which measures the difference in energy supplied to a substance and a reference material, as a function of temperature, allowing the evaluation of enthalpy variations over heating or cooling [11]. When the sample undergoes some kind of change in physical or chemical state, heat is released or absorbed. In compatibility studies the curves of the drug, excipients and mixtures are evaluated. Changes in drug melting point, peak shape and peak area together with changes in TGA may indicate possible interactions [3,12]. Physical interactions include: Glass transition, fusion, vaporization, sublimation, desorption and absorption, and chemical ones: Desolvation, dehydration and oxide-reduction reactions, which interactions should be evaluated as positive or not in the mixture. In the case of negatives there is an incompatibility between the drug and excipient.

For example, [13] evaluated the interaction between niclosamide with lactitol monohydrate povidone and PEG 6000 (1: $1, \mathrm{w} / \mathrm{w}$, ratio and ratio in which they exist in the dosage form). There was a strong interaction between niclosamide, povidone and polyethylene glycol (PEG6000), evidenced by the disappearance of the niclosamide peak in the thermograms of the mixtures. Such strong interactions are responsible for greater drug solubility and dissolution, thus, they are positive physical interactions. Study using thermo analytical and non-thermal techniques evaluated the compatibility of Granisetron hydrochloride with beta-Cyclodextrin, 2-hydroxypropyl-beta-cyclodextrin and mannitol [14]. The DSC showed incompatibility between the drug and all excipients selected by observing the formation of new events not present in the isolated thermograms. In contrast, non-thermal techniques showed compatibility, which reflects the low sensitivity compared to thermo analytical techniques. From this perspective, thermal analyses prove to be important tools for drug-excipient compatibility studies of both financial impact, predicting responses regarding the stability of a planned product, avoiding investment and time, and impacting health, elucidating possible interactions that would lead the pharmaceutical to exhibit low therapeutic efficacy and or toxicity to the administered patients. Moreover, as thermo analytical techniques should be expanded in the pharmaceutical field thanks to the speed of the responses, the minimum amount of information and predictive information for long-term conditions.

\section{References}

1. Dousa M, Gibala P, Havlícek J, Placek L, Tkadlecová M, et al. (2011) Drugexcipient compatibility testing - Identification and characterization of degradation products of phenylephrine in several pharmaceutical formulations against the common cold. Journal of Pharmaceutical and Biomedical Analysis 55(5): 949-956.

2. Matos APS (2012) Estudos de compatibilidade fármaco-excipiente e sua importância no desenvolvimento de formulações farmacêuticas.

3. Patel P, Ahir K, Patel V, Manani L, Patel C (2015) Drug-Excipient compatibility studies: First step for dosage form development The Pharma Innovation Journal 4(5): 14-20.

4. Pires FQ, Angelo T, Silva JKR, Barreto LCLS, Lima EM, et al. (2017) Use of mixture design in drug-excipient compatibility determinations: Thymol nanoparticles case study. Journal of Pharmaceutical and Biomedical Analysis 137: 196-203.

5. Trevor Lever PH, Rouquerol J, Charsley EL, Eckeren PV, Burlett DJ (2014) ICTAC nomenclature of thermal analysis (IUPAC Recommendations 2014). Pure Appl Chem 86(4): 545-553.

6. Yoshida MI, Oliveira MA, Gomes ECL, Mussel WN, Castro WV, et al. (2011) Thermal caracterization of lovastatin in pharmaceutical formulation. Journal of Thermal Analysis and calorimetry 106(3): 657-664.

7. Lima MSS, Da Cunha Filho AA, De Souza Araújo SF, Taveira RNM (2016) Evaluation of carvedilol compatibility with lipid excipients for the development of lipid-based drug delivery systems. J Therm Anal Calorim 123: 2337-2344.

8. Nisar J, Iqbal M, Iqbal M, Shah A, Akhter MS, et al. (2019) Decomposition Kinetics of Levofloxacin: Drug-Excipient Interaction. Z Phys Chem In press.

9. Corazzari I, Nistico R, Turci F, Faga MG, Franzoso F, et al. (2015) Advanced physico-chemical characterization of chitosan by means of TGA coupled on-line with FTIR and GCMS: thermal degradation and water adsorption capacity. Polym Degrad Stabil 112: 1-9.

10. Yoshida MI, Lima GEL, Vianna Soares CD, Cunha AF, Oliveira MA (2010) Thermal analysis applied to verapamil hydrochloride characterization in pharmaceutical formulations. Molecules 15: 2439- 2452.

11. Balestrieri F, Magri AD, Magri AL, Marini D, Sacchini A (1996) Application of differential scanning calorimetry to the study of drug-excipient compatibility. Thermochimica acta 285(2): 337-345.

12. Alves Silva I, Sá Barreto LCL, Lima EM, Cunha Filho MSS (2014) Preformulation studies of itraconazole associated with benznidazole and pharmaceutical excipients. Thermochim Acta 575: 29-33.

13. Malan CE, De Villiers MM, Lötter AP (1997) Application of differential scanning calorimetry and high performance liquid chromatography to determine the effects of mixture composition and preparation during the evaluation of niclosamide-excipient compatibility. J Pharm Biomed 15(4): 549-557.

14. Late SG, Banga AK (2008) Thermal and non-thermal methods to evaluate compat-ibility of granisetron hydrochloride with tablet excipients Pharmazie 63(6): 453-458. 


\section{ISSN: 2574-1241}

DOI: $10.26717 /$ BJSTR.2019.22.003745

Douglas Dourado. Biomed J Sci \& Tech Res

(c) (P) This work is licensed under Creative

Submission Link: https://biomedres.us/submit-manuscript.php

$\begin{array}{ll}\text { BIOMEDICAL } & \text { Assets of Publishing with us } \\ \text { RESEARCHES } & \text { - Global archiving of articles } \\ & \text { - Immediate, unrestricted online access } \\ \end{array}$

